\title{
Structure and composition of silicon nitride and silicon carbon nitride coatings for joint replacements
}

\author{
Maria Pettersson, Torun Berlind, Susann Schmidt, Staffan Jacobsson, Lars Hultman, Cecilia \\ Persson and Håkan Engqvist
}

\section{Linköping University Post Print}

\section{Tweet}

N.B.: When citing this work, cite the original article.

Original Publication:

Maria Pettersson, Torun Berlind, Susann Schmidt, Staffan Jacobsson, Lars Hultman, Cecilia Persson and Håkan Engqvist, Structure and composition of silicon nitride and silicon carbon nitride coatings for joint replacements, 2013, Surface \& Coatings Technology, (235), 25, 827834.

http://dx.doi.org/10.1016/j.surfcoat.2013.09.008

Copyright: Elsevier

http://www.elsevier.com/

Postprint available at: Linköping University Electronic Press

http://urn.kb.se/resolve?urn=urn:nbn:se:liu:diva-103351 


\title{
Structure and composition of silicon nitride and silicon carbon
}

\section{nitride coatings for joint replacements}

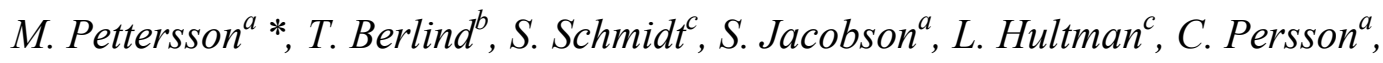 \\ and H. Engqvist ${ }^{a}$
}

${ }^{a}$ Division of Applied Materials Science, Department of Engineering Sciences, Uppsala University, Ångström Laboratory, 75121 Uppsala, Sweden.

${ }^{b}$ Applied Optics, Department of Physics, Chemistry and Biology (IFM), Linköping University,

58183 Linköping, Sweden.

${ }^{c}$ Thin Film Physics, Department of Physics, Chemistry and Biology (IFM), Linköping University, 58183 Linköping, Sweden.

*Corresponding author: e-mail address: maria.pettersson@angstrom.uu.se,

$$
\text { phone: }+46184717236
$$

\begin{abstract}
$\mathrm{SiN}_{\mathrm{x}}$ and $\mathrm{SiC}_{\mathrm{x}} \mathrm{N}_{\mathrm{y}}$ coatings were fabricated with high power impulse magnetron sputtering (HiPIMS). The coatings microstructure, growth pattern, surface morphology, composition, and bonding structure were investigated by AFM, SEM, GIXRD, TEM, EDS as well as XPS, and related to the deposition parameters target powers and substrate temperature. Crosssections of $\mathrm{SiC}_{\mathrm{x}} \mathrm{N}_{\mathrm{y}}$ coatings showed either dense and laminar, or columnar structures. These coatings varied in roughness (Ra between 0.2 and $3.8 \mathrm{~nm}$ ) and contained up to 35 at.\% C. All
\end{abstract}


coatings were substoichiometric (with an N/Si ratio from 0.27 to 0.65 ) and contained incorporated particles (so called droplets). The $\mathrm{SiN}_{\mathrm{x}}$ coatings, in particular those deposited at the lower power on the silicon target, demonstrated a dense microstructure and low surface roughness ( $\mathrm{Ra}$ between 0.2 and $0.3 \mathrm{~nm}$ ). They were dominated by an (X-ray) amorphous structure and consisted mainly of Si-N bonds. The usefulness of these coatings is discussed for bearing surfaces for hip joint arthroplasty in order to prolong their life-time. The long-term aim is to obtain a coating that reduces wear and metal ion release, that is biocompatible, and with wear debris that can dissolve in vivo.

Keywords: Silicon nitride coating; Silicon carbon nitride coating; High power impulse magnetron sputtering (HIPIMS); Total joint replacements; Microstructure. 


\section{Introduction}

Although total hip arthroplasty (THA) is considered a successful treatment and has been called the main surgical procedure in orthopedics [1], there is a significant amount of research on-going in order to increase the longevity of the implants. A high success rate of artificial hip joints is reported at 10 to 15 years [2], and commonly it is not the implant itself that wears out; it is the biological response to the wear debris that is the limiting factor [3]. Today, THA commonly has a metal-on-polymer bearing contact, with a cobalt chromium alloy $(\mathrm{CoCr})$ head and an ultra-high molecular weight polyethylene (UHMWPE) acetabular cup. However, UHMWPE wear debris may lead to inflammation, bone resorption, aseptic loosening [3-5], and later revision surgery.

As a consequence, alternative bearing contacts such as metal-on-metal, ceramic-on-ceramic and, ceramic-on-metal have been further developed. For metal-on-metal bearings, a small number of patients have experienced serious problems, such as soft tissue necrosis caused by wear debris, causing the governmental Medicines and Healthcare products Regulatory Agency (MHRA) in the UK to announce a first medical device alert on the subject 2010. Alumina $\left(\mathrm{Al}_{2} \mathrm{O}_{3}\right)$ is the most widely used ceramic material for the bearing contact in THA and has shown promising results in vivo [6,7], although brittle fracture is still a concern $[8,9]$. Silicon nitride $\left(\mathrm{Si}_{3} \mathrm{~N}_{4}\right)$ has been used for more than 50 years in extreme conditions in industrial applications, such as ball bearings and engines, due to its high fracture toughness, wear resistance, low density as well as chemical and thermal stability [10]. In water, silicon nitride can form a tribofilm that gives low friction and wear rates [11-13]. Silicon nitride is currently being introduced as a biomaterial [14-22]. A product based on silicon nitride got Food and Drug Administration (FDA) approval for use as spinal implants in 2006 and the first silicon nitride femoral head was implanted in early 2011 [23]. Silicon nitride has shown to be 
biocompatible [19] and recent studies have also shown better antibacterial and osteoinductive properties compared to titanium and polyether ether ketone (PEEK) [21, 22]. In an earlier publication by the authors [24], in vitro studies of blood plasma and antibody adsorption onto commercial silicon nitride surfaces were performed. Adsorption of blood plasma proteins indicated a good acceptance of silicon nitride in the body and a relatively low activity of the immune response compared to both titanium and zirconia $\left(\mathrm{ZrO}_{2}\right)$ [24]. Further, silicon nitride particles $(\sim 90 \mathrm{~nm})$ have been shown to dissolve in aqueous medium [25, 26], which suggests that wear debris can dissolve in vivo. This shows a potential to reduce the negative body response to any wear debris and possibly increase the longevity of the implant. Silicon nitride coatings have also been found to dissolve in an in vivo study in rats, with dissolution rates from 0.33 to $2.0 \mathrm{~nm} /$ day [27]. Hence, relatively thick coatings of several $\mu \mathrm{m}$ are likely required to withstand slow dissolution and this range of thicknesses is also recommended to provide sufficient wear life of ceramic coatings on hip implants [28-30].

A ceramic coating on a metal substrate could give a better implant performance in comparison to a bulk ceramic or metal, benefiting from the biocompatibility and wear resistance of the ceramic together with the toughness of the metal substrate. Furthermore, a ceramic coating can improve corrosion resistance and minimize metal ion release. A number of different coating compositions and deposition techniques have been studied for hip implants, the most common are titanium nitride (TiN), diamond-like carbon (DLC), zirconium oxide $\left(\mathrm{ZrO}_{2}\right)$, and chromium nitride (CrN) deposited by physical vapor deposition (PVD) or chemical vapor deposition (CVD) [29, 31-33]. However, the recently introduced coating systems $\operatorname{SiN}_{\mathrm{x}}$ and $\mathrm{SiC}_{\mathrm{x}} \mathrm{N}_{\mathrm{y}}$ are not yet well investigated for joint applications, in particular when produced by high power impulse magnetron sputtering (HiPIMS). This deposition method has been reported to form dense and smooth coatings on complex-shaped substrates [34]. In addition HiPIMS can be used to accomplish a good adhesion between coating and substrate, as well as 
to tailor the coating microstructure through the use of guided highly ionized plasma species [35-37]. One drawback for some material systems is the lower deposition rate of HiPIMS compared to conventional magnetron sputtering. Pusch et al. showed a significant difference in the structural properties of $\mathrm{SiC}_{\mathrm{x}} \mathrm{N}_{\mathrm{y}}$ coatings when comparing the deposition techniques radio frequency magnetron sputtering (RFMS), direct current magnetron sputtering (DCMS) and HiPIMS. Moreover, the hardness and elastic modulus of these coatings deposited by HiPIMS varied strongly depending on the carbon source[38].

In an earlier study by the authors, density functional theory (DFT) calculations showed that small amounts of substitutional carbon can destabilize crystalline silicon nitride, which indicates a possibility of tuning the dissolution rate [39]. Different carbon concentrations were therefore used in the current study with an aim of understanding how the addition of carbon would affect the microstructure and composition of silicon nitride coatings.

The aim of the present study is to relate the deposition parameters of HiPIMS deposited $\mathrm{SiN}_{\mathrm{x}}$ and $\mathrm{SiC}_{\mathrm{x}} \mathrm{N}_{\mathrm{y}}$ coatings to their structure and composition. A parallel study investigated the effect on the mechanical and tribological properties of the coatings [40]. The long term aim is to apply the coatings on $\mathrm{CoCr}$ alloys for medical implants. As inferred from above, potential advantages of silicon nitride include low wear rates and less wear particles, with a potential of slow dissolution in vivo. In this paper we refer mostly to hip implants, but the coating could be applicable to all joint replacements, such as knee, elbow, and extremities as well as to other parts of the implant such as the taper region etc.

The coatings were examined regarding morphology and surface roughness on the nanoscale using atomic force microscopy (AFM). Surface roughness is an important parameter as smooth surfaces can minimize later production steps. Also, smooth surfaces are generally 
required to obtain low wear rates and possibly full film lubrication. The growth pattern and morphology were studied by scanning electron microscopy (SEM) on cross-sections of the coatings. To evaluate the crystallinity of the coatings, grazing incidence X-ray diffraction (GIXRD) and transmission electron microscopy (TEM) were employed. Energy dispersive spectroscopy (EDS) was used to determine the chemical composition of the coatings and Xray photoelectron spectroscopy (XPS) for the bonding configuration.

\section{Materials and methods}

\subsection{Coating deposition}

Depositions were performed using an industrial coating system (CemeCon CC800/9 ML, Germany), using the same processes as described in [40]. The vacuum chamber of the industrial deposition system is equipped with four rectangular magnetron sputtering cathodes $(50 \times 8.8 \mathrm{~cm})$ facing a substrate holder in the center, where two of the cathodes can be run in HiPIMS mode. The pulse frequency was set to $300 \mathrm{~Hz}$, with a pulse width of $200 \mu \mathrm{s}$. Two of the magnetrons were used for the two types of depositions in this study; $\operatorname{SiN}_{\mathrm{x}}$ and $\mathrm{SiC}_{\mathrm{x}} \mathrm{N}_{\mathrm{y}}$ coatings. A Si target (purity 99.999\%) was used for all depositions, and for the latter depositions, a $\mathrm{C}$ target (purity 99.5\%) was also used for co-deposition. The two targets were positioned at a distance of $6 \mathrm{~cm}$ from the rotating substrate holder. For the $\mathrm{SiN}_{\mathrm{x}}$ coatings, the substrate had a stationary position, perpendicular to the Si target (later referred to as 'stationary'), and for the $\mathrm{SiC}_{\mathrm{x}} \mathrm{N}_{\mathrm{y}}$ coatings the substrates were rotated ('dynamic'). A pulsed bias voltage of $-100 \mathrm{~V}$ was applied to the substrates, synchronized with the cathode pulses. Two different substrate temperatures were used, $110^{\circ} \mathrm{C}$ and $430{ }^{\circ} \mathrm{C}$, later referred to as low $(l)$ and high $(h)$. The coatings were sputtered in an Ar- $\mathrm{N}_{2}$ atmosphere with a nitrogen fraction of 0.16. The power on the Si target was varied from $1 \mathrm{~kW}$ to $4 \mathrm{~kW}$ and the $\mathrm{C}$ target power from 0 to $1.4 \mathrm{~kW}$. The coatings are hereafter named after these deposition parameters, for example coating $\mathrm{SiCN}(4 / 0.7 / h)$ is a $\mathrm{SiC}_{\mathrm{x}} \mathrm{N}_{\mathrm{y}}$ coating deposited with an $\mathrm{Si}$ target power of $4 \mathrm{~kW}$ and $\mathrm{C}$ 
target power of $0.7 \mathrm{~kW}$ at a substrate temperature of $430^{\circ} \mathrm{C}$ while coating $\mathrm{SiN}(1 /-/ l)$ is a $\mathrm{SiN}_{\mathrm{x}}$ coating deposited with an Si target power of $1 \mathrm{~kW}$, stationary without employing the $\mathrm{C}$ target and at $110^{\circ} \mathrm{C}$.

All coatings were deposited on silicon wafers (001), to facilitate analysis after deposition. Substrates were individually cleaned ultrasonically in acetone and ethanol, in 5 min sequences, and dried in dry $\mathrm{N}_{2}$ gas before being introduced into the chamber. No pre-sputtering of the substrate surfaces was performed. The Si target power, the $\mathrm{C}$ target power and the substrate temperature were varied according to Table 1 (column 1) in order to vary the composition as well as the microstructure of the coatings.

\subsection{Structure and composition}

The morphology of the coatings was studied with AFM (Dimension 3100, Veeco Instruments, USA) operating in tapping mode and equipped with a Si tip delivered with a tip radius curvature less than $10 \mathrm{~nm}$ and a cone angle of $22^{\circ}$ (tip stiffness: 10-130 N/m, Nanosensors, Switzerland). Root mean square (rms) roughness and average roughness $(\mathrm{Ra})$ were evaluated from $1 x 1 \mu \mathrm{m}$ scans. Microstructure and thickness were examined by SEM (Leo 1550 FEG SEM Gemini, Carl Zeiss, Germany) on cross-sections of the coatings from a fracture of the Si (001). The cross-sections were either covered with a thin layer of $\mathrm{Pt}(\sim 10 \mathrm{~nm})$ or mounted on adhesive $\mathrm{Cu}$ tape to prevent charging. The amorphous (or crystal) structure was evaluated using GIXRD (Siemens D5000, Germany) at $1^{\circ}$ incidence angle. One coating was further examined using TEM (FEI Tecnai F30 ST, USA). The sample was prepared with a focused ion beam (FIB, FEI Strata DB235, USA) with an in-situ lift-out method. In order to assess the microstructure high resolution TEM (HRTEM) was performed along with selected area electron diffraction (SAED) using an energy filter (Gatan Imaging Filter (GIF) 2002, USA). EDS (EDAX Microanalysis, Netherlands) was employed in an SEM, with an acceleration 
voltage of $5 \mathrm{kV}$, to study the coating composition as well as investigating possible contaminations. The chemical bonding was examined using XPS (Physical Electronics (Phi) Quantum 2000, USA) with a monochromatic Al-K $\alpha$ source applying electron and ion neutralizer during measurements. Before the XPS measurements the samples were sputteretched with $\mathrm{Ar}^{+}$ions for $45 \mathrm{~min}$ at $200 \mathrm{eV}$ over $1 \mathrm{x} 1 \mathrm{~mm}$. Core level spectra were analyzed using the software XPS Peak and Gaussian curve shapes were fitted after Shirley background correction.

\section{Results}

\subsection{Structure}

Representative surface plots from AFM measurements are shown for selected $\mathrm{SiN}_{\mathrm{x}}$ and $\mathrm{SiC}_{\mathrm{x}} \mathrm{N}_{\mathrm{y}}$ coatings in Fig. 1. The surface plots show similar morphologies. However, smoother surfaces, with rms values ranging from 0.2 to $0.3 \mathrm{~nm}$, were revealed for $\mathrm{SiC}_{\mathrm{x}} \mathrm{N}_{\mathrm{y}}$ coatings deposited at the higher temperature using a high $\mathrm{Si}$ target power, and all $\mathrm{SiN}_{\mathrm{x}}$ coatings. Two examples of smooth surfaces are seen in Fig. 1a and 1f. Note that Fig. 1a is plotted with a smaller z-range in order to show that the smoother coatings had a similar morphology to the other coatings, but on a smaller scale. The remaining $\mathrm{SiC}_{\mathrm{x}} \mathrm{N}_{\mathrm{y}}$ coatings exhibited a rougher surface with rms values between 1.4 and $4.8 \mathrm{~nm}$, see Table 1 . The highest rms values were found for $\mathrm{SiC}_{\mathrm{x}} \mathrm{N}_{\mathrm{y}}$ coatings deposited at low temperature using a low Si target power, Fig. $1 \mathrm{~b}$ and 1d, Table 1. Varying amounts of incorporated particles were observed in the AFM measurements, one example can be seen in Fig. 1e. The roughness values from the AFM measurements presented in Table 1 were calculated in areas without droplets.

Fractured cross-sections, viewed in SEM, revealed a variation in surface morphology and microstructure of the coatings, Fig. 2. All $\mathrm{SiN}_{\mathrm{x}}$ coatings appeared smooth and showed a dense, homogeneous microstructure without indications of columnar growth, both at low and high 
temperatures. The thickness of these coatings varied between 1.2 and $4.4 \mu \mathrm{m}$, as presented in Table 1. For $\mathrm{SiC}_{\mathrm{x}} \mathrm{N}_{\mathrm{y}}$ coatings the power of the Si targets influenced the microstructure. $\mathrm{SiC}_{\mathrm{x}} \mathrm{N}_{\mathrm{y}}$ coatings deposited at lower Si target power $(1 \mathrm{~kW})$ exhibited a columnar microstructure, whereas an increased power $(4 \mathrm{~kW})$, generated a dense homogeneous microstructure with a superimposed laminar contrast. The thickness of the $\mathrm{SiC}_{\mathrm{x}} \mathrm{N}_{\mathrm{y}}$ coatings varied between 0.4 and $0.9 \mu \mathrm{m}$, see Table 1 . The surface morphology of $\mathrm{SiN}_{\mathrm{x}}$ and $\mathrm{SiC}_{\mathrm{x}} \mathrm{N}_{\mathrm{y}}$ coatings, determined by SEM, were divided into three groups in Table 1 . The coatings had a smooth appearance for all $\mathrm{SiN}_{\mathrm{x}}$ coatings and $\mathrm{SiC}_{\mathrm{x}} \mathrm{N}_{\mathrm{y}}$ coatings deposited at higher deposition temperatures combined with a high power of the Si target, $\operatorname{SiCN}(4 / 0.5-1.4 / h)$, Fig. $2 \mathrm{a}$ and $2 \mathrm{~d}$. With the lower deposition temperature, $\operatorname{SiCN}(4 / 0.5-1.4 / l)$, spherically shaped small nodules were observed on the surfaces, $20-50 \mathrm{~nm}$ in size. A similar morphology but with larger nodules, 50-100 nm, was observed on coatings grown at low Si target power, regardless of temperature for the $\mathrm{SiC}_{\mathrm{x}} \mathrm{N}_{\mathrm{y}}$ coatings, $\operatorname{SiCN}(1 / 0.7-1.4 / l)$ and $\operatorname{SiCN}(1 / 0.7-1.0 / h)$, Fig. 2b-c. These groups correlate to AFM surface plots in Fig. 1, where smooth is represented by Fig. 1a and 1f, small nodules by Fig. 1e and large nodules by Fig. 1b-d.

Both SEM and AFM studies showed varying amounts of droplets, with a size of $10 \mathrm{~nm}$ to 1 $\mu \mathrm{m}$, on the surfaces. Observations of $\mathrm{SiN}_{\mathrm{x}}$ coatings indicated that for higher Si target power more droplets had formed. The $\mathrm{SiC}_{\mathrm{x}} \mathrm{N}_{\mathrm{y}}$ coatings deposited at low Si target power showed a more limited amount of droplets, Fig. 3a. However, $\operatorname{SiCN}(1 / 0.7 / h)$, grown using the lowest powers of all coatings, still showed droplets. In Fig. 3b, a coating with a larger number of droplets is presented (denoted yes in Table 1, 'Droplets' column). Here, the molten nature of the droplets upon impact on the growing coating surface can be observed. The power on the $\mathrm{C}$ target did not seem to influence the amount of droplets. 
GIXRD analysis showed that all coatings were X-ray amorphous, although low intensity signals were obtained around 28 and $50^{\circ}$ for $\operatorname{SiN}(4 /-/ 1)$, $\operatorname{SiN}(2 /-/ h)$ and $\operatorname{SiN}(3 /-/ h)$. In addition, both HRTEM and SAED pattern of coating SiN (1/-/l) indicated an amorphous to nanocrystalline structure, see Fig. 4.

\subsection{Coating composition}

EDS analysis of the coating composition showed N/Si ratios between 0.27 and 0.65 , see

Table 1. The N/Si ratio decreased with increased Si target power and deposition temperature. In the $\mathrm{SiN}_{\mathrm{x}}$ coatings small amounts of $\mathrm{C}$ were also detected, within the margin of error. For the $\mathrm{SiC}_{\mathrm{x}} \mathrm{N}_{\mathrm{y}}$ coatings the $\mathrm{C}$ content is summarized in Table 1 . The $\mathrm{C}$ content increased from 6 at.\% to 35 at. $\%$ with increasing $\mathrm{C}$ target power as well as decreased Si target power. Traces of contaminating elements $\mathrm{Ar}, \mathrm{O}$ (and $\mathrm{C}$ for $\mathrm{SiN}_{\mathrm{x}}$ coatings) were detected in all coatings.

XPS analysis of the Si2p core level spectra demonstrated Si-N $(\sim 101.0 \mathrm{eV},[38,41])$ as a dominant bond in all coatings, Fig. 5a. For coatings deposited with a higher Si target power, the $\mathrm{Si} 2 \mathrm{p}$ peaks were broader, indicating contributions from the Si-Si bond ( $99.5 \mathrm{eV},[42])$ see Fig. 5a. Presumably the component assigned to Si-C bonds $(\sim 100.3 \mathrm{eV})$ is concealed within the intense signals from $\mathrm{Si}-\mathrm{N}$ and $\mathrm{Si}-\mathrm{Si}$ bonds and can therefore not be resolved for the $\mathrm{SiC}_{\mathrm{x}} \mathrm{N}_{\mathrm{y}}$ coatings. The $\mathrm{Si}-\mathrm{N}$ bonds were confirmed by photo electron peaks for N1s $(\sim 397.4$ eV, [38]), Fig. 5b. Coatings deposited at higher Si target power contained more Si and also a higher intensity component assigned Si-Si bonds. There was no signal obtained from Si-O bonds, see Fig. 5a.

In the $\mathrm{C} 1 \mathrm{~s}$ core level spectra the $\mathrm{SiC}_{\mathrm{x}} \mathrm{N}_{\mathrm{y}}$ coatings with higher $\mathrm{C}$ content (over 10 at. $\%$ in Table 1) showed C-Si bonds ( $282.8 \mathrm{eV},[38,41])$, Fig. 5c. For coatings with the highest $\mathrm{C}$ content, $\mathrm{SiCN}(1 / 1.0-1.4 / l)$ and $\mathrm{SiCN}(1 / 1.0 / h)$, a possible double peak was recorded. The two 
peaks were likely formed from a large $\mathrm{C}$-Si peak along with a $\mathrm{C}-\mathrm{C}$ peak $(\sim 284.5 \mathrm{eV},[38,41])$. At an intermediate C content, samples $\operatorname{SiCN}(1 / 0.7 / l$ and $h)$ and $\operatorname{SiCN}(4 / 1.4 / l$ and $h)$, distinct C-Si bonds were found, while the contributions from C-C bonds were small or non-detectable. A higher ratio of C-Si bonds (and less $\mathrm{C}-\mathrm{C}$ bonds) was formed at higher temperature and lower C target power, while the Si target power has no significant impact on the intensity of the component assigned to these bonds. The intensity of the $\mathrm{C}$ peaks in the XPS correlates to the $\mathrm{C}$ signal from the EDS analysis. Coatings with a low $\mathrm{C}$ content (less than 10 at. $\%$ in Table 1) showed no distinct $\mathrm{C}$ peak for $\mathrm{C} 1 \mathrm{~s}$ and was for that reason not included in Fig. 5c. Small amounts of contaminating elements ( $\mathrm{O}$ and $\mathrm{Ar})$ were detected in all coatings, which were also detected with EDS. An overview of how the structure and composition changed with the deposition parameters is displayed in Fig. 6 and 7, for $\mathrm{SiN}_{\mathrm{x}}$ and $\mathrm{SiC}_{\mathrm{x}} \mathrm{N}_{\mathrm{y}}$ coatings, respectively.

\section{Discussion}

\subsection{Structure}

The coating thickness differed between individual coatings due to the variation in deposition time and deposition rate. The deposition rate increased with the Si target power. The substrate temperature did not influence the deposition rate to a great extent. A difference in deposition rate was seen between coatings deposited in a stationary or dynamic (rotation) mode. The deposition rate varied from similar to up to 25 times higher for stationary deposition. This is attributed to the fact that during depositions employing sample rotation, the samples faced the cathodes only a fraction of the time compared to depositions where they were stationary. Compared to r.f. sputtered $\mathrm{SiN}_{\mathrm{x}}$ coatings [39], the HiPIMS deposited $\mathrm{SiN}_{\mathrm{x}}$ coatings had up to 10 times higher deposition rate. The $\mathrm{SiC}_{\mathrm{x}} \mathrm{N}_{\mathrm{y}}$ coatings deposited with rotation had a similar rate as the r.f. sputtered. Even though a low deposition rate can be a concern for HiPIMS, it was not found to be a major issue in this study. In order to increase the deposition rate further, 
more targets can be used or deposition parameters such as target power or pulse frequencies could be tuned.

Low $\mathrm{Ra}$ and rms values of coatings deposited on Si are promising for joint bearing applications [32, 43-45]. However, when deposited on CoCr substrates, which are rougher than Si-wafers, the surface roughness of the coating will also increase. For the $\mathrm{SiN}_{\mathrm{x}}$ coatings none of the deposition parameters appeared to influence the surface roughness. However, for the $\mathrm{SiC}_{\mathrm{x}} \mathrm{N}_{\mathrm{y}}$ coatings, which showed a generally higher roughness, two of the deposition parameters - Si target power and substrate temperature - appeared to have an effect on the roughness. At a higher Si target power and/or a higher temperature, smoother surfaces were obtained. According to Thornton's zone model a higher deposition temperature results in lower surface roughness and denser structure, since it enables atoms or ions to find more energetically favorable positions on the surface [46], including filling surface vacancies and cusps.

Different types of microstructures were formed in the $\mathrm{SiC}_{\mathrm{x}} \mathrm{N}_{\mathrm{y}}$ coatings depending on the $\mathrm{Si}$ target power: at the lower power a columnar microstructure was formed, and at the higher power a laminar microstructure was found. In comparison to r.f. sputtered $\mathrm{SiN}_{\mathrm{x}}$ coatings [39], all HiPIMS deposited $\mathrm{SiN}_{\mathrm{x}}$ coatings were more homogenously dense and did not have a pronounced columnar growth pattern. However, HiPIMS deposited $\mathrm{SiC}_{\mathrm{x}} \mathrm{N}_{\mathrm{y}}$ appeared more porous in cross-section than the r.f. sputtered $\mathrm{SiN}_{\mathrm{x}}$ coatings. Droplet formation is a concern since the droplets could contribute to coating failure by acting as corrosion paths, giving rise to local stresses and an increased fracture risk under loading, or an increase in wear. Generally droplets are not a major issue for HiPIMS, but can emerge due to dust particles or molten splashes when a conductive target has been covered with an insulating layer [47]. A possibility to limit droplet formation could be to use shorter pulses during deposition, which 
can prevent glow-to-arc transition [47-49]. Droplets on the $\mathrm{SiN}_{\mathrm{x}}$ coatings indicate that higher Si target power causes the formation of more droplets. Our current assumption is that a higher Si target power causes increased arcing, which leads to local target melting and ejection of particles that are incorporated into the growing coatings. Still, SiCN $(1 / 0.7 / h)$, grown using the lowest Si target power, showed droplets. Only SiN (1/-/l) showed a very limited amount of droplets.

When changing the deposition from stationary $\left(\mathrm{SiN}_{\mathrm{x}}\right.$ coatings $)$, to dynamic $\left(\mathrm{SiC}_{\mathrm{x}} \mathrm{N}_{\mathrm{y}}\right.$ coatings $)$ and introducing the $\mathrm{C}$ target, the microstructure changed. For the $\mathrm{SiN}_{\mathrm{x}}$ coatings, no notable difference in microstructure was observed for different power and/or temperature settings, all cross-sections showed dense coatings. On the other hand, for $\mathrm{SiC}_{\mathrm{x}} \mathrm{N}_{\mathrm{y}}$ coatings, a lower $\mathrm{Si}$ target power resulted in columnar and more porous structures, whereas a higher Si power caused a denser structure without pronounced columns. It was also found that an increased deposition temperature resulted in a slightly denser structure for columnar structures, seen in Fig. 2b-c. A distinct laminar structure due to the substrate rotation and direction dependent deposition flux, could be observed for $\mathrm{SiC}_{\mathrm{x}} \mathrm{N}_{\mathrm{y}}$ coatings deposited at a Si target power of $4 \mathrm{~kW}$, but not for those with the lower Si target power of $1 \mathrm{~kW}$. At $1 \mathrm{~kW}$, it is possible that a laminar structure is present, but is simply not resolved in the SEM.

All coatings were X-ray amorphous. Coating SiN (1/-/l), studied in TEM, showed an amorphous to nanocrystalline structure. Nanocrystals possibly occur, especially for $\mathrm{SiN}_{\mathrm{x}}$ coatings that show slight signals in the XRD spectra. These coatings were deposited at a higher temperature and/or at a higher Si target power. This is in agreement with literature, as it suggests higher deposition temperatures and nitrogen fractions for the formation of a crystalline (or polycrystalline) $\mathrm{Si}_{3} \mathrm{~N}_{4}$ structure [10, 50, 51]. For implant applications, an amorphous structure may be an advantage compared to a polycrystalline structure, as an 
amorphous structure generally is more uniform with less corrosion paths such as grain boundaries [32]. The X-ray amorphous structure in these coatings has shown a similar wear rate to crystalline $\mathrm{Si}_{3} \mathrm{~N}_{4}$, however a higher coefficient of friction was noted [40].

\subsection{Coating composition}

The coatings had a low $\mathrm{N} / \mathrm{Si}$ ratio $(0.29$ to 0.65$)$ compared to stoichiometric $\mathrm{Si}_{3} \mathrm{~N}_{4}(1.33)$. For higher Si target power and higher substrate temperature, more Si was detected in the coating. In order to obtain information from the coating and not from the substrate, a low acceleration voltage $(5 \mathrm{kV})$ was used for the EDS analysis. An electron flight simulation based on a Monte Carlo model at this voltage estimates an information depth in $\mathrm{Si}_{3} \mathrm{~N}_{4}$ of $0.3 \mu \mathrm{m}$. This elemental analysis should be used for comparison between samples in this study and not as absolute quantitative values, as no references were used and signals from light elements such as $\mathrm{C}$ and $\mathrm{N}$ can be difficult to detect.

By varying deposition parameters, the $\mathrm{C}$ content could be tuned up to approximately 35 at. \%. According to earlier DFT calculations [39], the surface reactivity - and consequently also the dissolution rate - of crystalline $\mathrm{Si}_{3} \mathrm{~N}_{4}$ can be increased by the addition of small amounts $(1,3$, and 4 at. \%) of substitutional C. Tuning of the dissolution rate may be required in order to make it fast enough to avoid negative effects from the wear debris, and slow enough to ensure an adequate longevity of the coating. The calculations apply to $\mathrm{C}$ bonded to $\mathrm{Si}$, and not $\mathrm{C}-\mathrm{C}$. XPS measurements in this work showed C-Si bonds if a lower $\mathrm{C}$ target power and/or a higher Si target power along with a higher deposition temperature were used. The calculations made in the previous study were made on stoichiometric, crystalline $\mathrm{Si}_{3} \mathrm{~N}_{4}$, in contrast to the (X-ray) amorphous coatings with another N/Si-ratio, which may affect the dissolution rate. 
There are two possible Ar contamination sources, both from the deposition process and/or pre-sputtering in the XPS analysis. However, since Ar was also detected in EDS, the deposition definitely is one of them. $\mathrm{O}$, but also $\mathrm{N}$ and $\mathrm{C}$, are likely to originate from ambient contamination. The risk of sputter damage was minimized as far as possible for the XPS analysis through the use of low ion energy. [52]

The $\mathrm{SiN}_{\mathrm{x}}$ coatings showed little dependence on deposition parameters such as contaminating elements, morphology, microstructure, N-Si bonds, or surface roughness. Neither did the varying coating thickness appear to affect the chemical and structural analysis.

\subsection{Effect on mechanical properties}

For $\mathrm{SiN}_{\mathrm{x}}$ coatings, the mechanical properties and the chemistry can be related to the Si target power. At lower Si target power, a higher N/Si ratio as well as a higher quota of Si-N bonds and lower of Si-Si bonds was obtained, which possibly explains the slight increase from 17 to $21 \mathrm{GPa}$ in coating hardness [40]. The hardness effect is likely to be related to the chemistry since structural properties such as the surface roughness and cross-section microstructure were similar for all $\mathrm{SiN}_{\mathrm{x}}$ coatings.

The high surface roughness, for coatings $\operatorname{SiCN}(1 / 0.7-1.4 / l)$ compared to the other $\operatorname{SiC}_{\mathrm{x}} \mathrm{N}_{\mathrm{y}}$ could possibly explain the lower hardness (10-11 GPa vs. 15-21 GPa) and elastic modulus (140-150 GPa vs. 170-220 GPa) measured on these coatings [40]. The hardness measurements were made at a maximum depth of $40 \mathrm{~nm}$, where the high surface roughness could have affected the measurement (Fig. $1 \mathrm{~b}$ and 1d).

In general it was found that the deposition parameters, such as target power and the combination of different targets, strongly affected the structure and composition of the coating, 
and in turn the mechanical properties. As for the specific wear rate it appears that the dense structure obtained for $\mathrm{SiN}_{\mathrm{x}}$ coatings can give a better performance than the less dense structures found for $\mathrm{SiC}_{\mathrm{x}} \mathrm{N}_{\mathrm{y}}$ coatings [40]. This also motivates more in depth investigation on the $\mathrm{N}$ content along with the microstructure, and hence the mechanical properties.

\section{Conclusions}

$\mathrm{SiN}_{\mathrm{x}}$ and $\mathrm{SiC}_{\mathrm{x}} \mathrm{N}_{\mathrm{y}}$ coatings were fabricated using HiPIMS for joint bearing surfaces. The coatings were examined for their microstructure, surface appearance and composition. $\mathrm{SiN}_{\mathrm{x}}$ coatings were smooth and showed a dense, homogeneous microstructure with thicknesses between 1.2 and $4.4 \mu \mathrm{m} . \mathrm{SiC}_{\mathrm{x}} \mathrm{N}_{\mathrm{y}}$ coatings varied in roughness, where higher deposition temperature and lower Si target power resulted in smoother coatings. The thickness of the coatings ranged between 0.4 and $0.9 \mu \mathrm{m} . \mathrm{SiC}_{\mathrm{x}} \mathrm{N}_{\mathrm{y}}$ coatings exhibited two types of microstructure: columnar (deposited at Si target power $1 \mathrm{~kW}$ ) and dense/layered (deposited at Si target power $4 \mathrm{~kW}$ ). All coatings contained droplets on the surface, the amount of droplets increased with higher Si target power.

The coatings were (X-ray) amorphous and had a low N/Si ratio, from 0.27 to 0.65 . The ratio decreased with increased Si target power and deposition temperature. The Si-N bond was the most dominant bonding type for $\mathrm{Si}$ in all coatings but when a higher power was used on the $\mathrm{Si}$ target, an increasing amount of $\mathrm{Si}-\mathrm{Si}$ bonds were formed. For $\mathrm{SiN}_{\mathrm{x}}$ coatings, no notable difference was found for coatings deposited at different temperatures. $\mathrm{SiC}_{\mathrm{x}} \mathrm{N}_{\mathrm{y}}$ coatings with up to 35 at.\% C were produced. An increased power on the Si target and an increased deposition temperature resulted in more $\mathrm{Si}-\mathrm{C}$ bonds (less $\mathrm{C}-\mathrm{C}$ bonds), and vice versa.

Findings in this paper support further development of these coatings for surfaces in joint replacements. Especially the $\mathrm{SiN}_{\mathrm{x}}$ coatings are of interest since they have shown to be dense 
with low surface roughness, in particular coatings grown at lower Si target power for a minimized amount of droplets. Future research will focus on investigating the dissolution rates of wear particles and coatings together with biological reactions. Also, further development in terms of thicker coatings and improved adhesion is needed, as well as an increased understanding of the influence of $\mathrm{N}$ concentration and the $\mathrm{N}$ bonding structure.

\section{Acknowledgements}

The authors are grateful for the financial support from the Swedish Foundation for Strategic Research (SSF) through the Materials Program for Nanoscale Surface Engineering $\left(\mathrm{MS}^{2} \mathrm{E}\right)$ and the synergy Project FUNCASE. The authors would also like to acknowledge Kathryn Grandfield and Thomas Thersleff for assisting with the FIB and TEM work, respectively. 


\section{Reference}

[1] J.P. Courpied, J.H. Caton, International Orthopaedics (SICOT), 35 (2011) 149-150.

[2] G. Garellick, J. Kärrholm, C. Rogmark, P. Herberts, Swedish Hip Arthroplasty Register Annual Report 2010, 2011.

[3] E. Ingham, J. Fisher, Proceedings of the Institution of Mechanical Engineers, Part H: Journal of Engineering in Medicine, 214 (2000) 21-37.

[4] E. Ingham, J. Fisher, Biomaterials, 26 (2005) 1271-1286.

[5] H.C. Amstutz, P. Campbell, N. Kossovsky, I.C. Clarke, Clinical Orthopaedics \& Related Research, (1992) 7-18.

[6] B.E. Bierbaum, J. Nairus, D. Kuesis, J.C. Morrison, D. Ward, Clinical Orthopaedics \& Related Research, 405 (2002) 158-163.

[7] P.J. Lusty, C.C. Tai, R.P. Sew-Hoy, W.L. Walter, W.K. Walter, B.A. Zicat, The Journal of Bone \& Joint Surgery, 89 (2007) 2676-2683.

[8] D.P. Rhoads, K.C. Baker, R. Israel, P.W. Greene, The Journal of Arthroplasty, 23 (2008) e25-30, 1239.

[9] K. Iwakiri, H. Iwaki, Y. Minoda, H. Ohashi, K. Takaoka, Clinical Orthopaedics and Related Research, 466 (2008) 1186-1192.

[10] F.L. Riley, Journal of the American Ceramic Society, 83 (2000) 245-265.

[11] T. Sugita, K. Ueda, Y. Kanemura, Wear, 97 (1984) 1-8.

[12] T.E. Fischer, H. Tomizawa, Wear, 105 (1985) 29-45.

[13] Y.S. Zhou, M. Ohashi, N. Tomita, K. Ikeuchi, K. Takashima, Materials Science and Engineering: C, 5 (1997) 125-129.

[14] M.N. Rahaman, A. Yao, B.S. Bal, J.P. Garino, M.D. Ries, Journal of the American Ceramic Society, 90 (2007) 1965-1988.

[15] B.S. Bal, A. Khandkar, R. Lakshminarayanan, I. Clarke, A.A. Hoffman, M.N. Rahaman, The Journal of Arthroplasty, 24 (2009) 110-116.

[16] B.S. Bal, A. Khandkar, R. Lakshminarayanan, I. Clarke, A.A. Hoffman, M.N. Rahaman, Journal of Biomedical Materials Research Part B: Applied Biomaterials, 87B (2008) 447-454.

[17] M. Mazzocchi, A. Bellosi, Journal of Materials Science: Materials in Medicine, 19 (2008) 28812887.

[18] M. Mazzocchi, D. Gardini, P. Traverso, M. Faga, A. Bellosi, Journal of Materials Science: Materials in Medicine, 19 (2008) 2889-2901.

[19] B.S. Bal, M. Rahaman, The Rationale for Silicon Nitride Bearings in Orthopaedic Applications, in: C. Sikalidis (Ed.) Advances in Ceramics - Electric and Magnetic Ceramics, Bioceramics, Ceramics and Environment, InTech, Bioceramics, Ceramics and Environment, 2011.

[20] B.S. Bal, M.N. Rahaman, Acta Biomaterialia, 8 (2012) 2889-2898. 
[21] D.J. Gorth, S. Puckett, B. Ercan, T.J. Webster, M. Rahaman, B.S. Bal, International Journal of Nanomedicine, 7 (2012) 4829-4840.

[22] T.J. Webster, A.A. Patel, M.N. Rahaman, B.S. Bal, Acta Biomaterialia, 8 (2012) 4447-4454.

[23] AMEDICA/US SPINE Enters the Reconstructive Surgery Market: First Silicon Nitride Total Hip Replacement,

http://www.amedicacorp.com/press_releases/amedica_us_spine_enters_the_reconstructive_surgery_m arket, Published: 2011-02-17, Accessed: 2013-08-06.

[24] J. Olofsson, M. Grehk, T. Berlind, C. Persson, S. Jacobson, H. Engqvist, Biomatter, 2 (2012) 94102.

[25] E. Laarz, B.V. Zhmud, L. Bergström, Journal of the American Ceramic Society, 83 (2000) 23942400 .

[26] B.V. Zhmud, L. Bergström, Journal of Colloid and Interface Science, 218 (1999) 582-584.

[27] J.M. Maloney, S.A. Lipka, S.P. Baldwin, Materials Research Society Symposium Proceedings, 872 (2005) 1-6.

[28] T. Röstlund, B. Albrektsson, T. Albrektsson, H. McKellop, Biomaterials, 10 (1989) 176-181.

[29] J. Fisher, X.Q. Hu, J.L. Tipper, T.D. Stewart, S. Williams, M.H. Stone, C. Davies, P. Hatto, J. Bolton, M. Riley, C. Hardaker, G.H. Isaac, G. Berry, E. Ingham, Proceedings of the Institution of Mechanical Engineers, Part H: Journal of Engineering in Medicine, 216 (2002) 219-230.

[30] J. Fisher, X.Q. Hu, T.D. Stewart, S. Williams, J.L. Tipper, E. Ingham, M.H. Stone, C. Davies, P. Hatto, J. Bolton, M. Riley, C. Hardaker, G.H. Isaac, G. Berry, Journal of Materials Science: Materials in Medicine, 15 (2004) 225-235.

[31] I. Gotman, E.Y. Gutmanas, G. Hunter, 1.108 - Wear-Resistant Ceramic Films and Coatings, in: D. Editor-in-Chief: Paul (Ed.) Comprehensive Biomaterials, Elsevier, Oxford, 2011, pp. 127-155.

[32] R. Lappalainen, S.S. Santavirta, Clinical Orthopaedics and Related Research, 430 (2005) 72-79.

[33] M.K. Harman, S.A. Banks, W.A. Hodge, The Journal of Arthroplasty, 12 (1997) 938-945.

[34] J. Alami, P.O.A. Persson, D. Music, J.T. Gudmundsson, J. Bohlmark, U. Helmersson, Journal of Vacuum Science \& Technology A: Vacuum, Surfaces, and Films, 23 (2005) 278-280.

[35] A.P. Ehiasarian, P.E. Hovsepian, L. Hultman, U. Helmersson, Thin Solid Films, 457 (2004) 270277.

[36] A.P. Ehiasarian, J.G. Wen, I. Petrov, Journal of Applied Physics, 101 (2007) 054301.

[37] J. Alami, S. Bolz, K. Sarakinos, Journal of Alloys and Compounds, 483 (2009) 530-534.

[38] C. Pusch, H. Hoche, C. Berger, R. Riedel, E. Ionescu, A. Klein, Surface and Coatings Technology, 205, Supplement 2 (2011) S119-S123.

[39] J. Olofsson, M. Pettersson, N. Teuscher, A. Heilmann, K. Larsson, K. Grandfield, C. Persson, S. Jacobson, H. Engqvist, Journal of Materials Science: Materials in Medicine, 23 (2012) 1879-1889.

[40] M. Pettersson, S. Tkachenko, S. Schmidt, T. Berlind, S. Jacobson, L. Hultman, H. Engqvist, C. Persson, Journal of the Mechanical Behavior of Biomedical Materials, 25 (2013) 41-47. 
[41] W.-S. Cho, Y.-S. Oh, C.-S. Kim, M. Osada, M. Kakihana, D.-S. Lim, D.-S. Cheong, Journal of Alloys and Compounds, 285 (1999) 255-259.

[42] J.F. Moulder, W.F. Stickle, P.E. Sobol, K.D. Bomben, Handbook of X-ray photoelectron spectroscopy, Physical Electronics,Inc., Eden Prairie, Minnesota, 1995.

[43] A.W. Eberhardt, R.T. McKee, J.M. Cuckler, D.W. Peterson, P.R. Beck, J.E. Lemons, International Journal of Biomaterials, 2009 (2009) 1-6.

[44] J. Fisher, L. Jennings, A. Galvin, Wear of Highly Crosslinked Polyethylene against Cobalt Chrome and Ceramic femoral heads Bioceramics and Alternative Bearings in Joint Arthroplasty, in: F. Benazzo, F. Falez, M. Dietrich (Eds.) Bioceramics and Alternative Bearings in Joint Arthroplasty, Steinkopff, Steinkopff Verlag, Darmstadt, 2006, pp. 185-188.

[45] Y.-H. Kim, A. Ritchie, C. Hardaker, The Journal of Bone \& Joint Surgery, 87 (2005) 577-582.

[46] J.A. Thornton, Journal of Vacuum Science and Technology, 11 (1974) 666-670.

[47] K. Sarakinos, J. Alami, S. Konstantinidis, Surface and Coatings Technology, 204 (2010) 16611684.

[48] A. Anders, Surface and Coatings Technology, 204 (2010) 2864-2868.

[49] M. Ganciu, S. Konstantinidis, Y. Paint, J. Dauchot, M. Hecq, L. de Poucques, P. Vasina, M. Mesko, J. Imbert, J. Bretagne, M. Touzeau, Journal of Optoelectronics and Advanced Materials, 7 (2005) 2481-2484.

[50] L.C. Chen, C.Y. Yang, D.M. Bhusari, K.H. Chen, M.C. Lin, J.C. Lin, T.J. Chuang, Diamond and Related Materials, 5 (1996) 514-518.

[51] B.K. Yen, R.L. White, R.J. Waltman, Q. Dai, D.C. Miller, A.J. Kellock, B. Marchon, P.H. Kasai, M.F. Toney, B.R. York, H. Deng, Q.-F. Xiao, V. Raman, Journal of Vacuum Science \& Technology A: Vacuum, Surfaces, and Films, 21 (2003) 1895-1904.

[52] E. Lewin, M. Gorgoi, F. Schäfers, S. Svensson, U. Jansson, Surface and Coatings Technology, 204 (2009) 455-462. 
Table 1. Summary of observations by SEM (thickness, microstructure, morphology and droplets), AFM (average and root mean square roughness) and EDS (composition).

\begin{tabular}{|c|c|c|c|c|c|c|c|c|c|}
\hline $\begin{array}{l}\text { Coating Name } \\
\text { (Si-target power }[\mathrm{kW}] / \\
\text { C-target power }[\mathrm{kW}] / \\
\text { Temp.) }\end{array}$ & Thickness & $\begin{array}{l}\text { Deposition } \\
\text { rate }\end{array}$ & $\mathrm{Ra}$ & Rms & Morphology & Droplets & Microstructure & N/Si-ratic & C content \\
\hline $\operatorname{SiN}(1 /-/ l)$ & 1.2 & 0.7 & 0.3 & 0.3 & smooth & very limited & dense & 0.42 & 1 \\
\hline $\operatorname{SiN}(2 /-/ l)$ & 2.8 & 1.6 & 0.2 & 0.3 & smooth & limited & dense & 0.32 & 2 \\
\hline $\operatorname{SiN}(3 /-/ l)$ & 4.3 & 2.4 & 0.2 & 0.2 & smooth & yes & dense & 0.31 & 1 \\
\hline $\operatorname{SiN}(4 /-/ l)$ & 4.4 & 2.4 & 0.3 & 0.3 & smooth & yes, a lot & dense & 0.29 & 0 \\
\hline $\operatorname{SiN}(2 /-/ h)$ & 2.5 & 1.4 & 0.2 & 0.2 & smooth & yes & dense & 0.31 & 1 \\
\hline $\operatorname{SiN}(3 /-/ h)$ & 3.8 & 2.1 & 0.2 & 0.3 & smooth & yes & dense & 0.27 & 1 \\
\hline $\operatorname{SiCN}(4 / 0.5 / l)$ & 0.50 & 0.33 & 1.3 & 1.6 & small nodules & yes & dense/laminar & 0.37 & 6 \\
\hline $\operatorname{SiCN}(4 / 0.7 / l)$ & 0.65 & 0.50 & 1.4 & 1.7 & small nodules & yes & dense/laminar & 0.38 & 9 \\
\hline $\operatorname{SiCN}(4 / 1.4 / l)$ & 0.55 & 0.42 & 1.1 & 1.4 & small nodules & yes & dense/laminar & 0.35 & 14 \\
\hline $\operatorname{SiCN}(1 / 0.7 / l)$ & 0.55 & 0.14 & 3.3 & 4.2 & nodules & limited & columnar & 0.57 & 23 \\
\hline $\operatorname{SiCN}(1 / 1.0 / l)$ & 0.40 & 0.10 & 3.4 & 4.3 & nodules & limited & columnar & 0.65 & 30 \\
\hline $\operatorname{SiCN}(1 / 1.4 / l)$ & 0.85 & 0.22 & 3.8 & 4.8 & nodules & limited & columnar & 0.65 & 35 \\
\hline $\operatorname{SiCN}(4 / 0.5 / h)$ & 0.80 & 0.35 & 0.2 & 0.3 & smooth & yes & dense/laminar & 0.34 & 6 \\
\hline $\operatorname{SiCN}(4 / 0.7 / h)$ & 0.90 & 0.39 & 0.2 & 0.2 & smooth & yes & dense/laminar & 0.27 & 9 \\
\hline $\operatorname{SiCN}(4 / 1.4 / h)$ & 0.70 & 0.33 & 0.2 & 0.2 & smooth & yes & dense/laminar & 0.27 & 15 \\
\hline $\operatorname{SiCN}(1 / 0.7 / h)$ & 0.70 & 0.13 & 1.7 & 2.1 & nodules & yes & columnar & 0.53 & 22 \\
\hline $\operatorname{SiCN}(1 / 1.0 / h)$ & 0.70 & 0.13 & 2.3 & 2.9 & nodules & limited & columnar & 0.57 & 29 \\
\hline
\end{tabular}



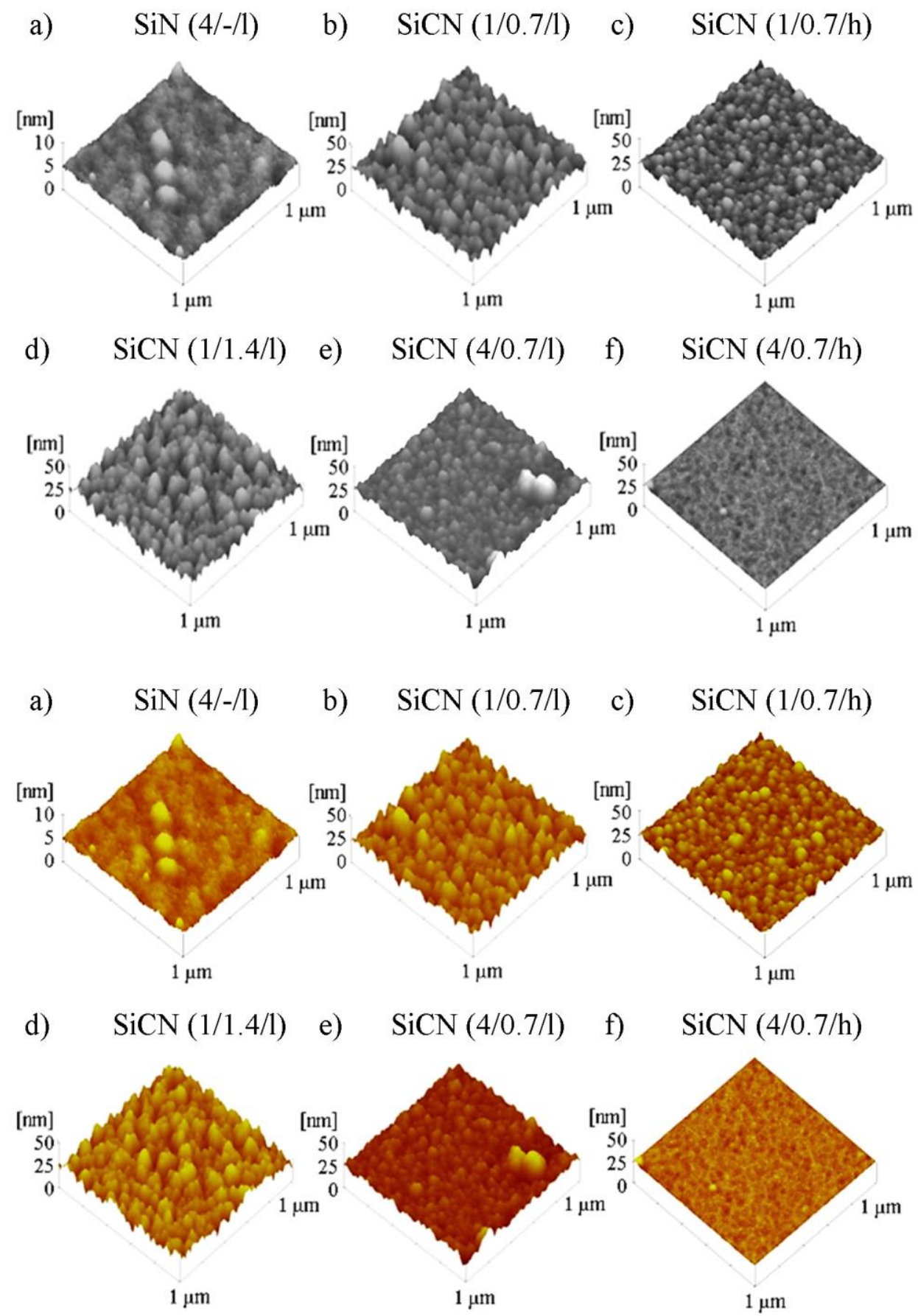

Fig. 1. AFM surface plots $(1 \mathrm{x} 1 \mu \mathrm{m})$ of representative coatings with a $\mathrm{z}$-scale of $5 \mathrm{~nm}$ (a) and $25 \mathrm{~nm}$ (b-f) per division. The images represent smooth surfaces (a and f), with small nodules (e) and with nodules (b-d). A surface with droplets is shown in (e). 


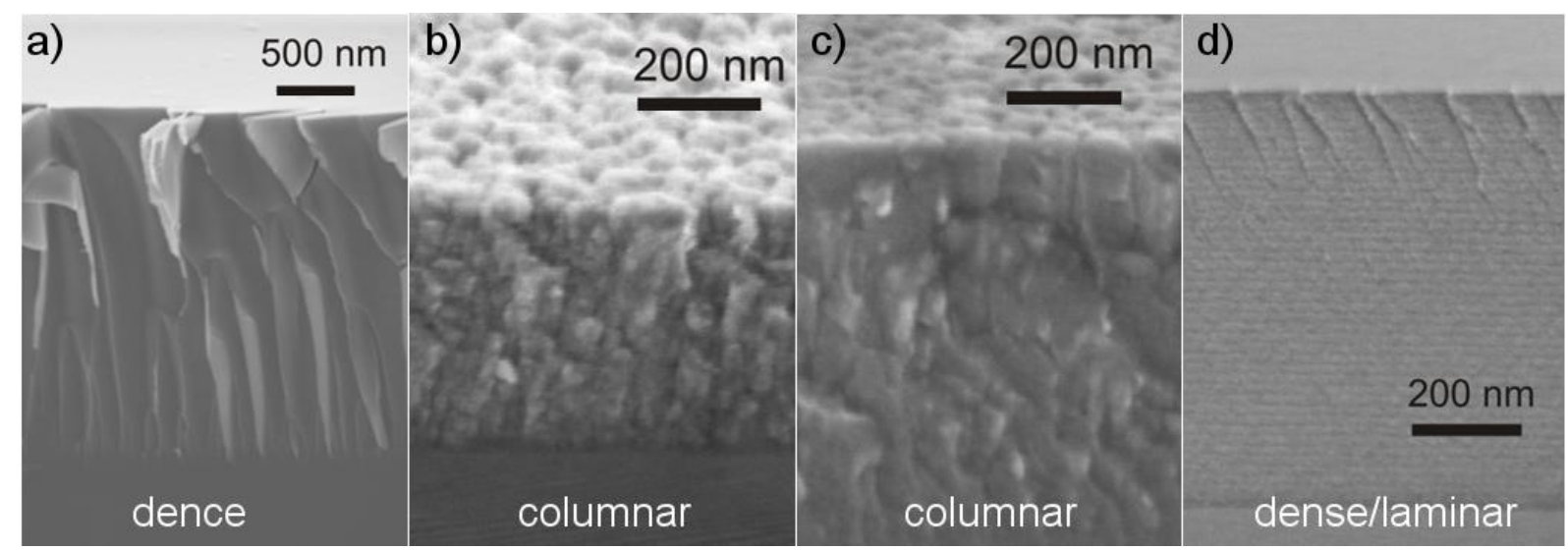

Fig. 2. Fractured cross-sections viewed in SEM where a) represent a dense homogeneous microstructure, $\mathrm{SiN}(2 /-/ h), \mathrm{b}-\mathrm{d})$ a columnar microstructure, in $\mathrm{SiCN}(1 / 1.0 / l)$ and $\mathrm{SiCN}$ $(1 / 1.0 / h)$, while d) represents a laminar microstructure, in $\operatorname{SiCN}(4 / 0.5 / h)$.

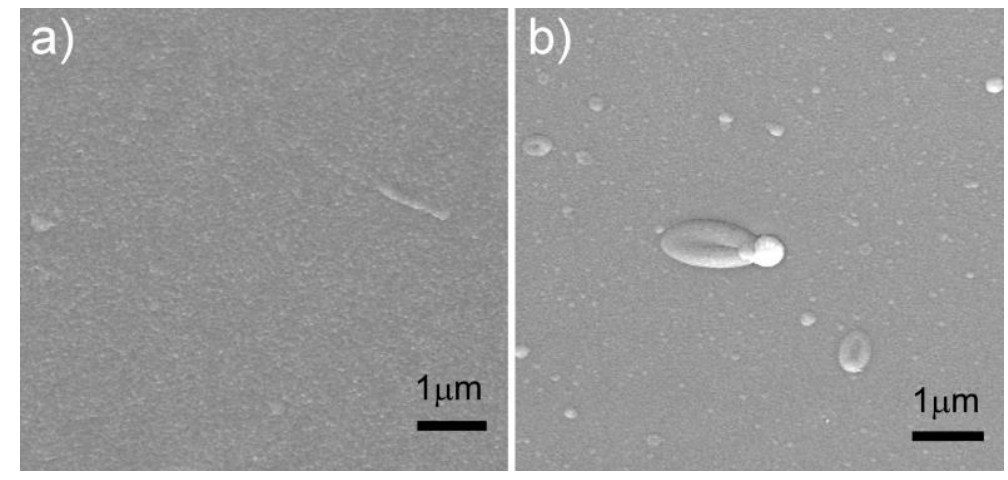

Fig. 3. Droplets studied in SEM are described as a) a surface with limited amount of droplets and in b) surfaces with droplets to a higher extent.

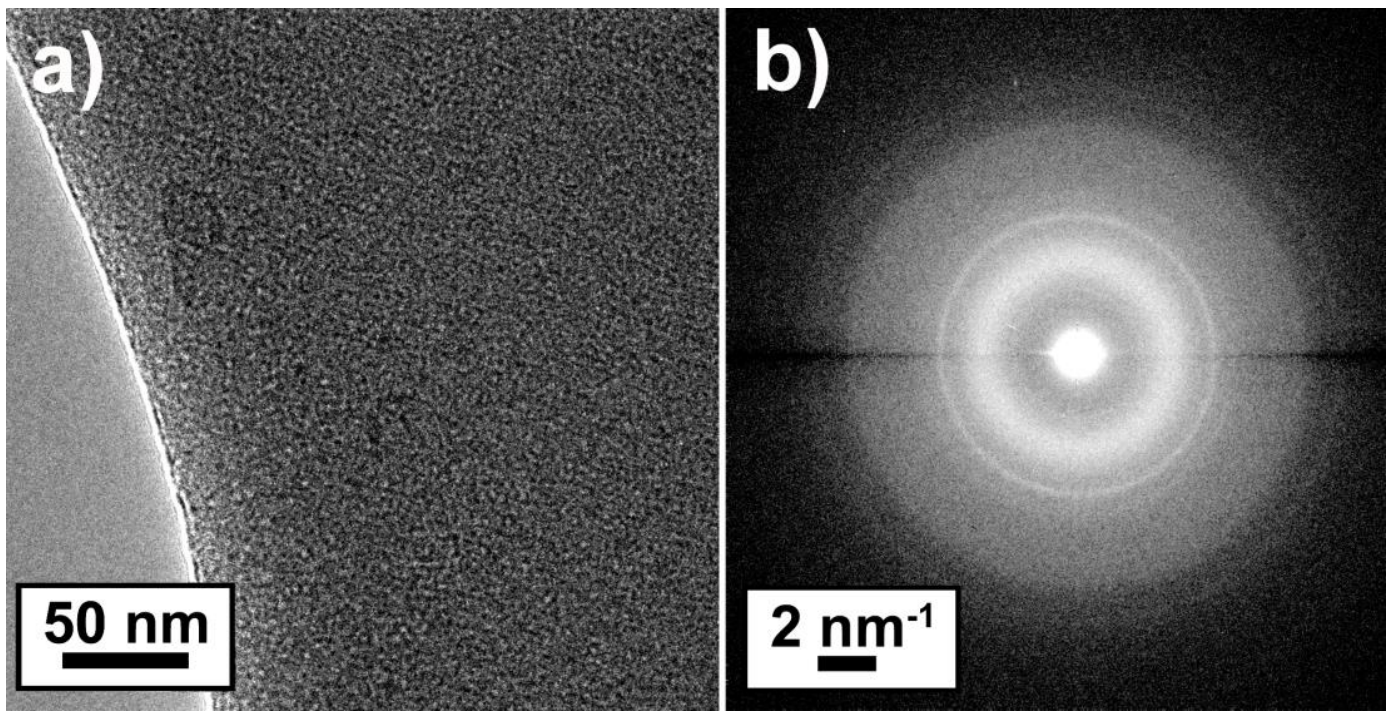

Fig. 4. HRTEM image of coating $\operatorname{SiN}(1 /-/ l)$ obtained at defocus near the coating surface (a), and a SAED pattern, confirming an amorphous to nanocrystalline structure (b). 

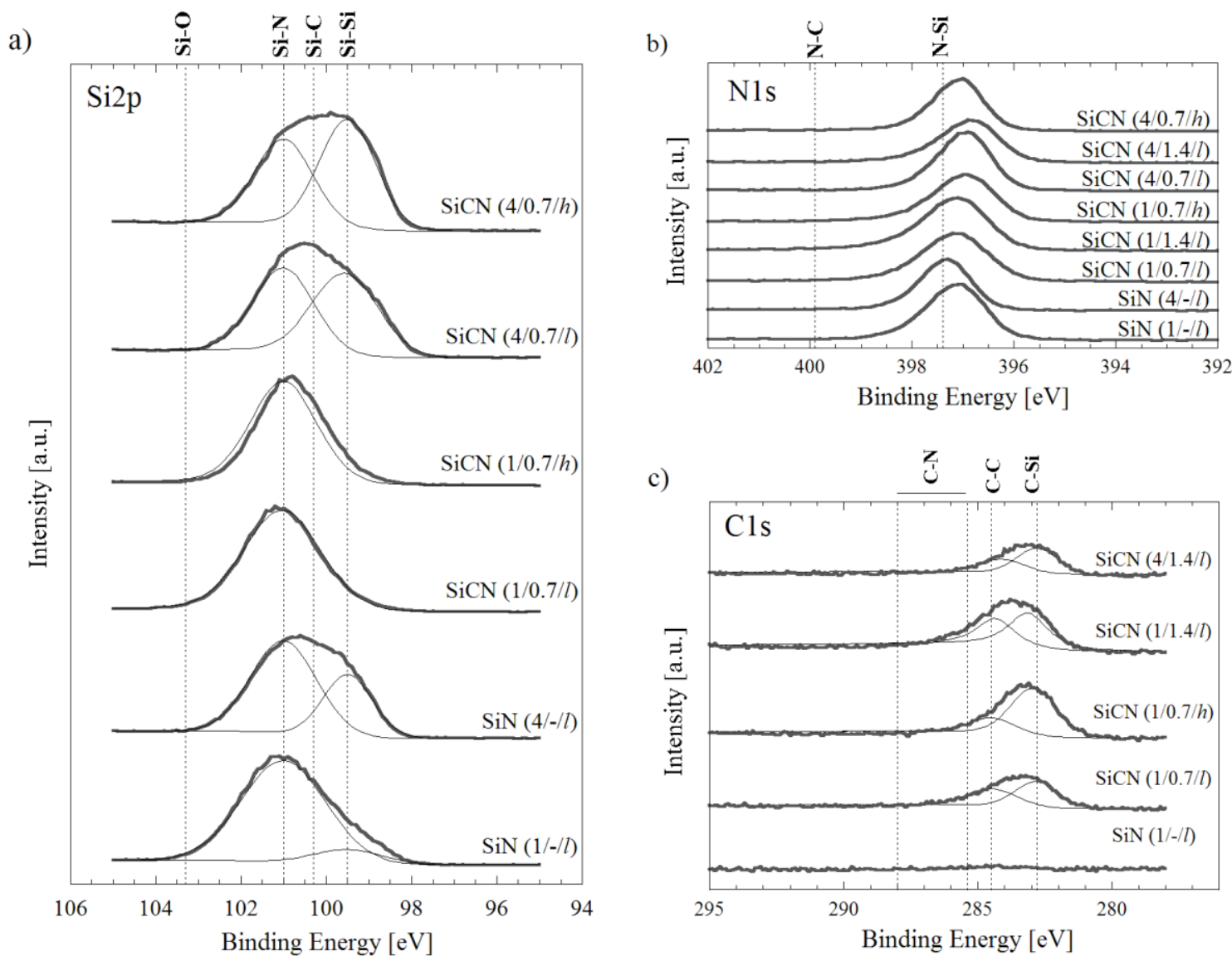

Fig. 5. XPS core level spectra of a) Si2p, b) N1s and c) C1s for selected $\operatorname{SiN}_{x}$ and $\operatorname{SiC}_{x} N_{y}$ coatings with varying deposition parameters, where the thick gray lines show the measured data and the thin black lines shows fitted peaks. 


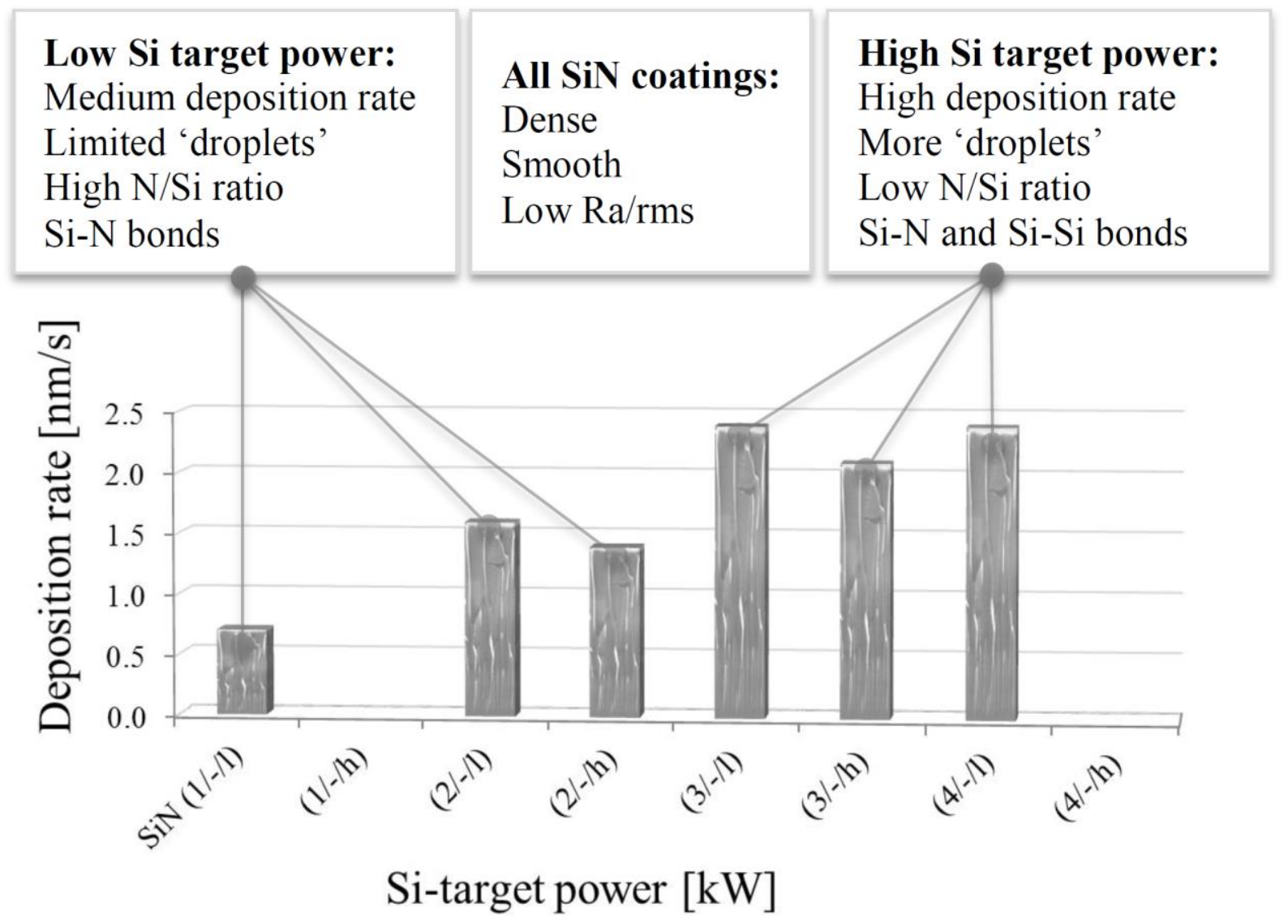

Fig. 6. Overview of structures and compositions of $\mathrm{SiN}_{\mathrm{x}}$ coatings depending on the target power and substrate temperature. 


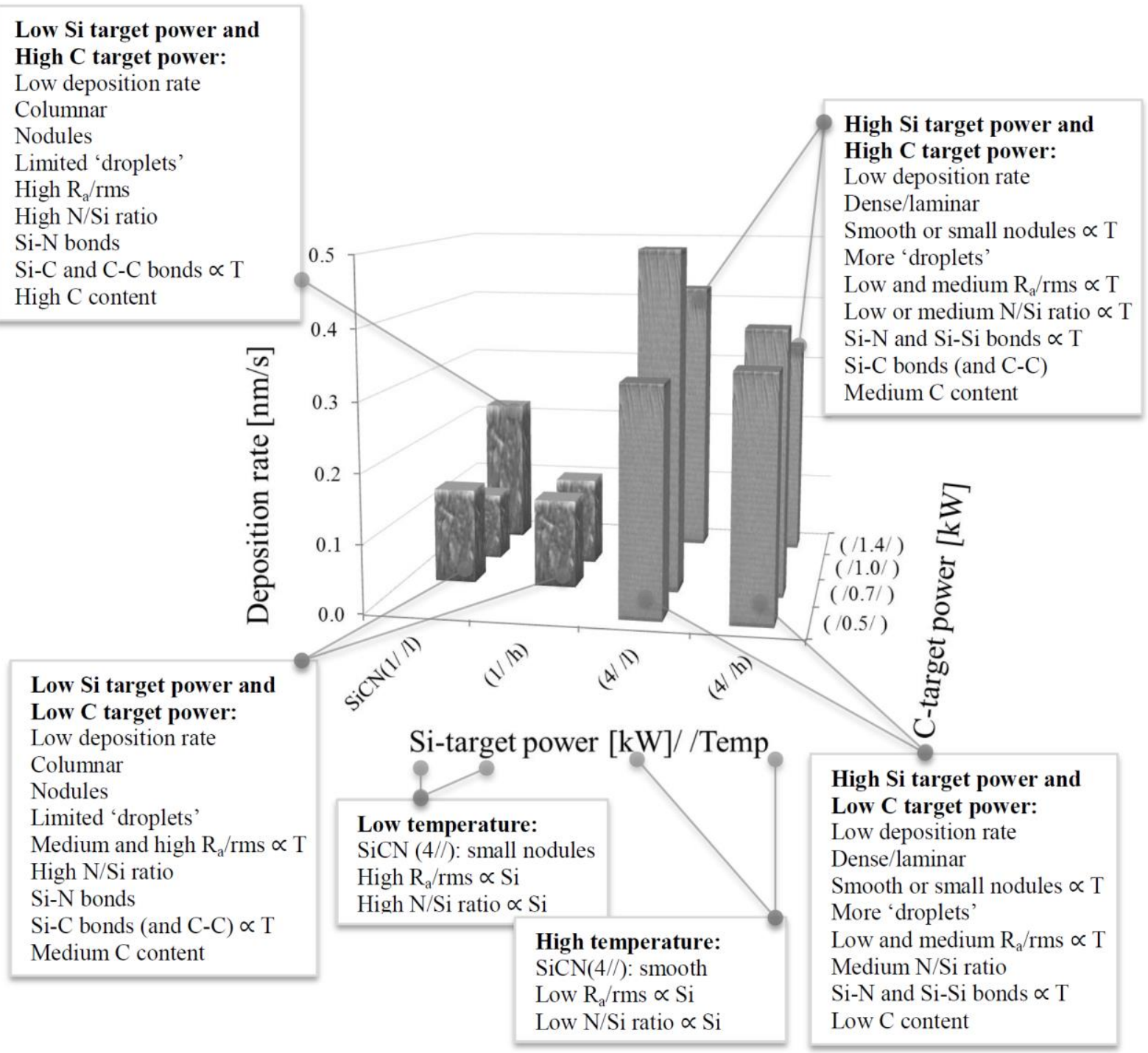

Fig. 7. Overview of structures and compositions of $\operatorname{SiC}_{\mathrm{x}} \mathrm{N}_{\mathrm{y}}$ coatings depending on the target power and substrate temperature. When marked ' $\propto \mathrm{T}$ ' or ' $\propto \mathrm{Si}$ ', temperature or Si-target power also affect this property. 